\title{
The Weiguan Culture Phenomenon in Chinese Online Activism
}

\author{
Bao Han \\ Department of Digital Humanities \\ King's College London \\ London, UK \\ https://www.researchgate.net/profile/Han-Bao-22 \\ han.bao@kcl.ac.uk
}

\author{
Jonathan $P$. Bowen \\ School of Engineering \\ London South Bank University \\ London, UK \\ http://www.jpbowen.com \\ jonathan.bowen@Isbu.ac.uk
}

\begin{abstract}
'Weiguan' is a cultural phenomenon that involves drawing a crowd to observe a problematic event or issue, while not becoming involved. In this paper, we examine online Weiguan as the expression of China's collective consciousness captured in a moment that is emotionally mobilised by a collective chattering. We argue that it involves judgements, cognition solutions, blame, and actions, even when under media state political censorship, but crucially never forming into organising solutions, outside collective actions, or protest responses. We also consider online Weiguan in the context of citizen journalism (eyewitness reporting, and independent investigation initiated by public citizens) combined with emotional structure, exploring the mobilization of an emotional medium of collective memories and collective action in the public sphere.
\end{abstract}

Online activism. Online Weiguan. Political communication. China. Digital culture.

\section{BACKGROUND}

Activism is an important cultural activity, including in the arts (Giannini 2019; Giannini \& Bowen 2019a). The increasing prevalence of digital culture (Bowen \& Giannini 2014; 2021; Giannini \& Bowen $2019 \mathrm{~b})$ has changed the nature of activism, enabling new ways of undertaking protest. The use of modern communication technologies effectively initiates and manages many social and civic protest movements and is commonly referred to as digital activism (Han 2021). It has enabled new more direct ways of motivating the public. For example, awareness of the lack of funding for the wartime site of Bletchley Park was increased using social media such as Twitter (Black et al. 2010; Black \& Colgan 2015). This is the site where Alan Turing worked on decrypting German Enigma messages during World War II. Through public support including online publicity, this heritage site has now been saved for posterity (Greenish et al. 2017). Turing himself has been the focus for public activism due to his persecution by the UK government in the early 1950 s as a gay man. This has more recently lead to pardons for those in the gay community, including Turing in particular, from the UK government and the Queen, following by a change in the law dubbed "Turing's Law" concerning homosexuality (Bowen \& Copeland 2017; Han 2018).
Different parts of the world have different cultural aspects to activism, including online, depending on the social and political situation that is prevalent. This paper is concerned with developments in China, which has many differences compared to the West. Ai Weiwei is perhaps the most wellknown Chinese activist in the art world. He combines his activism and art. An example of his artwork is a panda stuffed with shredded sensitive US material exposed by Edward Snowden, as exhibited at the Victoria and Albert Museum in London during 2018 (see Figure 1).

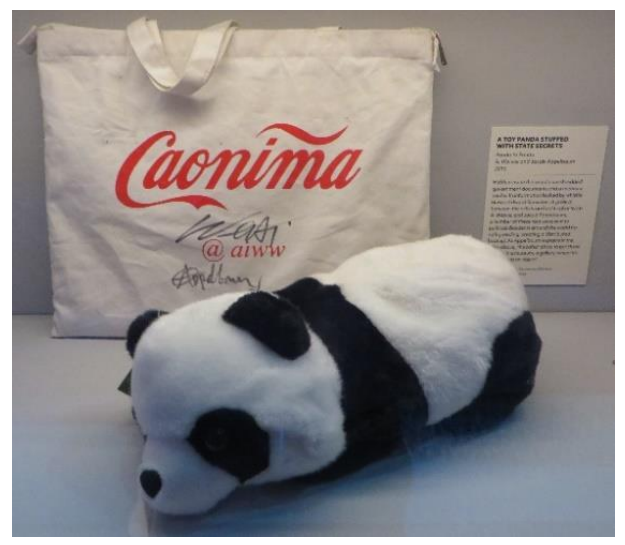

Figure 1: "A Toy Panda Stuffed with State Secrets", by Ai Weiwei and Jacob Appelbaum (2015). (Photograph by Jonathan Bowen, 2018.) 
Online citizen activism takes place in China through social media such as Weibo and WeChat (Han 2021), despite the digital nationalism of the Chinese government (Schneider 2018). Western causes such as the \#MeToo hashtag movement aimed at improving women's empowerment through social media (Giannini 2019) have also had an effect in China (Han 2019). The rest of this paper concentrates on a particular Chinese phenomenon that is known as "Weiguan" in China (Xu 2015; 2016; 2018), where the public avoids involvement with difficult events. We especially consider aspects concerning online digital culture.

\section{THE WEIGUAN PHENOMENON}

Wéiguān (围观) is a cultural phenomenon, as argued by Xu (2015), meaning the drawing a crowd of people to see a problematic event or issue, while not being involved in any way in trying to solve the problem by intervening in the event itself. This phenomenon is perhaps best known in the West as an exaggerated version of the 'passer-by effect'. Examples include the Peng Yu incident in 2006 and the death of Wang Yue in 2011, where Good Samaritans who helped people injured in accidents were accused of having injured the victim themselves.

In the latter case above, Wang Yue (王悦; Wáng Yuè), commonly referred to as "Little Yue Yue" (小 悅悅), was born in 2009 and struck by two cars in Guangdong province two years later. Passengers nearby choose to ignore her little body in the middle of the road for a few minutes until a garbage collector helped to send her to hospital. Unfortunately, she died a week later, and the recorded footage stimulated numerous discussions globally.

The term 'Weiguan', literally translates as a "surrounding gaze" (Bandurski 2011) and refers generally to a group or crowd activity that occurs around unscripted public events in public places. As a popular term, it describes the drawing of mass attention in a random manner within public spaces, while avoiding involvement in the event (Xu 2015).

According to $\mathrm{Xu}$ (2018), the Weiguan cultural phenomenon is first quoted by China's important literary figure Xun Lu (1881-1936), who wrote about the Weiguan phenomenon in his 1919 novelette "Medicine" (Yao, 药) (see Figures 2-4). "Medicine" is a short story telling of deprived illiterate parents using a great fortune to purchase bloody bread, with a belief that it could treat tuberculosis, with the blood from an executed warrior martyr. In this fictional account, $\mathrm{Xu} \mathrm{Lu}$ vividly depicts a crowd of traumatised and numb
Chinese people dumbly observing the decapitation of the warrior martyr Yu Xia, who had fought for their liberation and freedom.

Xun Lu (1919) criticised the culture of the gaze (Kanke wenhua, 看客文化), involving looking without action in Chinese society. It reflected the ignorance, impassiveness, conservativeness, and feudal nature of ordinary people; they were silent curious spectators in public but gossiped about events in private. The rituals from feudal China continued to remain as a powerful cultural current in China's collective action into the post-revolutionary age. For example, during the 1960s Cultural Revolution, small groups of Mao's Red Guard enacted, in their revolutionary and cultist fervour, forms of powerful emotional mobilisation and terror among large crowds of people, who watched in Weiguan inactivity. Lu Xun believed that if a revolutionary movement could unite ordinary Chinese people and transform them from passive onlookers or spectators to active participants, it would succeed. He criticised the fact that the 1911 revolution was unsuccessful due to a lack of grass roots popular support to deliver enough sustainable progress.

There are cultural undercurrents reflected in Chinese literature like the short story of "Medicine" by Lu (1919). It also has more fragmented historical origins, the official legislative mechanisms in its use of letter petitioning. Letters and visit systems (Xinfangzhidu, 信访制度) played a significant role in tackling the inequalities and corruptions experienced by citizens.

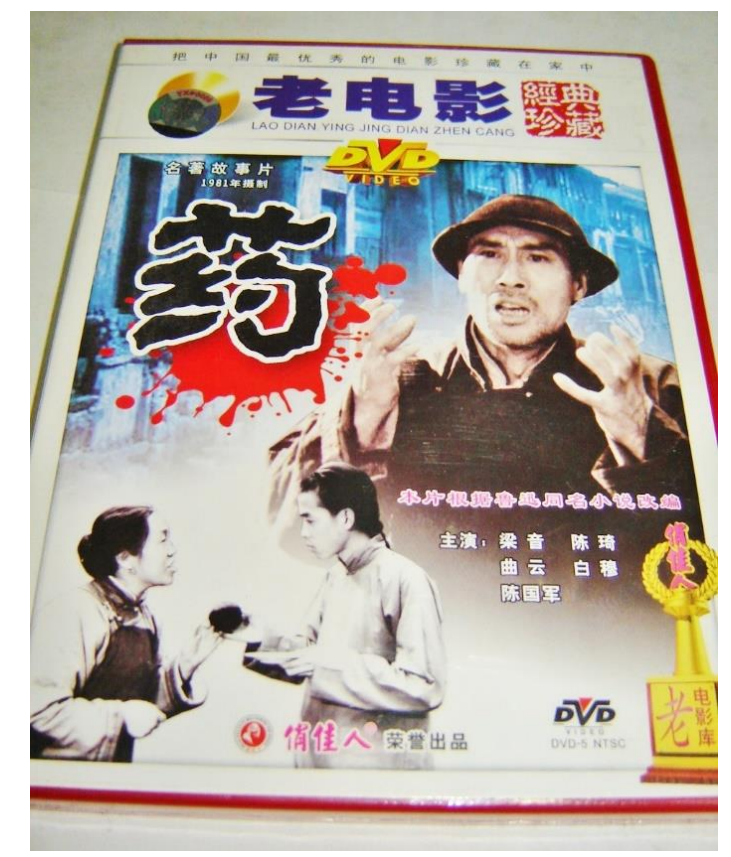

Figure 2: Old Chinese film poster based on the Yao (Medicine) novel by Lu Xun.

(https://www.amazon.com/Medicine-xuns-novel-ChineseFilm/dp/7884086778) 


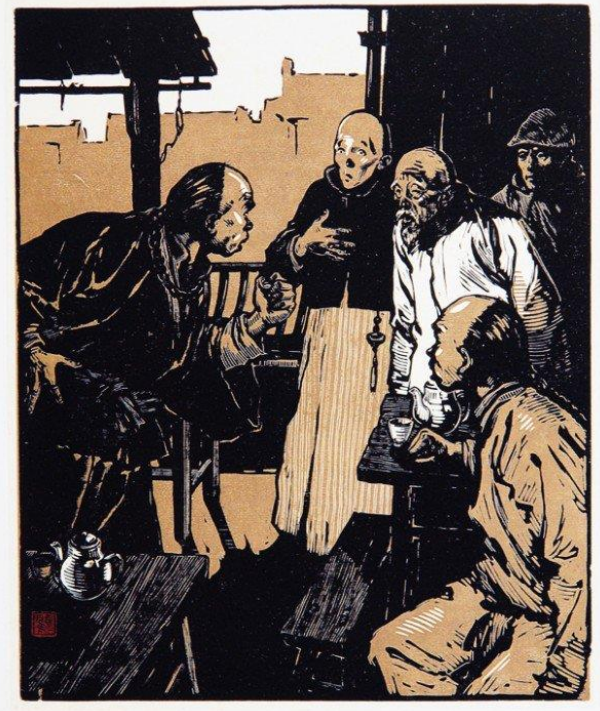

Figure 3: Illustration from the 1919 Yao (Medicine) novel by Lu Xun.

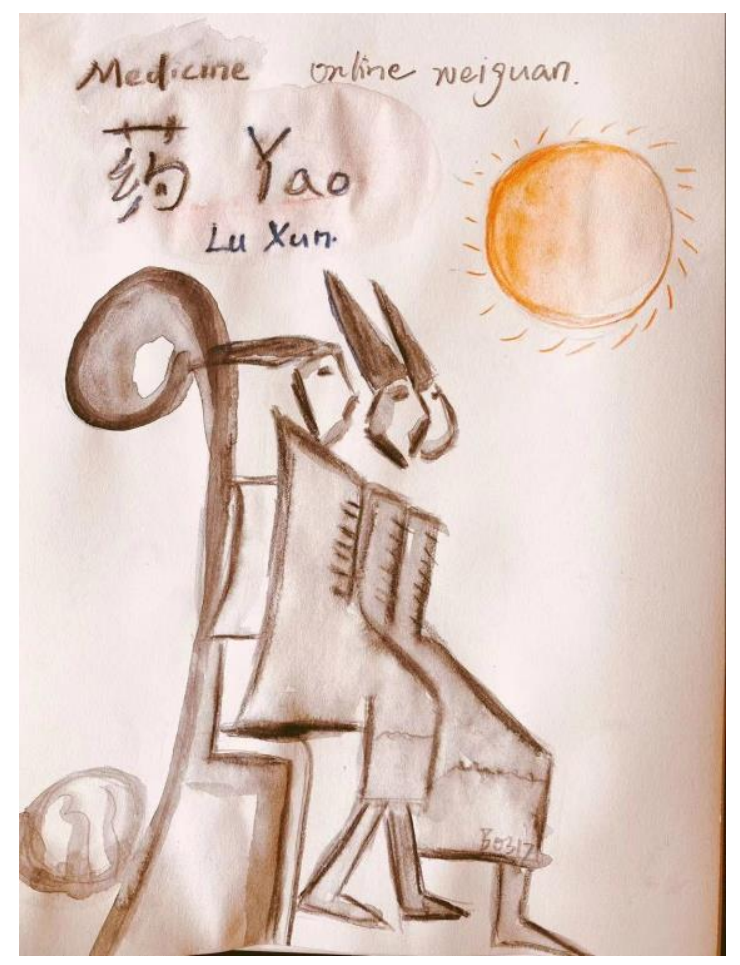

Figure 4: Yao (Medicine) novel by Lu Xun. (Drawing by Bao Han, 2021.)

On 1 October 2017, the Weiguan phenomenon was acknowledged as a societal issue by being enshrined in Chinese law. China's 'Good Samaritan act' (Article 184 in General Provisions of the Civil Law) is intended to protect citizens and tasks them with a general duty to act, as well as promoting citizens to be active bystanders in order to protect others (NPC 2017):

Article 184: A person shall not bear civil liability for acting voluntarily to help another in an emergency and thus causes damage to the person being helped.
This issue is known as the "bystander effect" in psychological studies, a type of communal paralysis, where citizens relinquish responsibility, especially in crowds, resulting in large groups acting only as observers of crimes, and not being responsive to people in distress in public places.

\section{WEIGUAN AND THE BYSTANDER EFFECT}

In general, the bystander effect refers to a mass of civilians refraining from interfering in an urgent situation, usually within a crowd of strangers. Sometimes called bystander apathy, Darley and Latané (1968) were the first to demonstrate, formulate, and study the bystander phenomenon. The relevance today to studies of crowd mentality can be reflected in offline and online behaviours, both in their similarities and differences. A psychological consciousness of being in the presence of other people, usually strangers, influences an individual's behaviour and the likelihood of helping a person who is in an emergency situation. There are two key aspects here to the study, firstly the intervention of technology by the recording of events as a smartphone 'activity' while being part of a gawping crowd and secondly the cultural differences between countries; the determinant differences between the Western identification of the bystander effect and Weiguan is in its cultural effects in China.

In firstly examining these cultural differences, an example here is the case of Wang Yue who is normally referred to as "Little Yue Yue", as mentioned earlier. She was only aged two when closed-circuit television recorded her distressing incident. The video footage was disseminated and stimulated overwhelming responses worldwide. The unfortunate, yet popular conclusion in understanding the indifference to a child injured and at-risk was one of the consequences. It is highly likely to result in trouble with the authorities in their attempts to establish a "harmonious" society, so feeling unable to help has become normalised behaviour in China. Yan (2010) indicated the rationales behind similar behaviours through different psychological identification with acquaintances and strangers, which is deeply rooted in the traditional Chinese mindset.

The Chinese sociologist Fei (1947) argued that there is a clear difference between Eastern and Western religions, especially in unanimous love, which refers to paying equal attention to one's surroundings. $\mathrm{He}$ also mentioned the responsibilities of which individuals should be aware at the family and societal levels. The set of rules within and outside a certain community can be vastly different, making it easy to discern the outsider in a traditional community. 
Chinese society is proudly obsessive in its materialistic advancement but equally ashamed and often shocked by the feudal and rural peasant behaviours that are still present. How to best eradicate these 'backward mentalities' is a constant theme in popular internet discourse. Chinese authorities recognise that conventional local groups are not helpful in the development of the modern dream of much of Chinese society. To amend this situation, government departments and officials have used the tools available to them in an authoritarian system, by seeking strict solutions to disciplining bystanders who are ignorant of similar cases. The "Good Samaritan" Law was announced to punish those who reject helping others in emergencies.

\section{ONLINE WEIGUAN}

The online Weiguan (网络围观) phenomenon specifically alludes to new media events in China's Web 2.0 culture where a virtual crowd gathers in cyberspace on the Weibo or WeChat social media platforms to discuss events of public social concern that form as an immediate public consciousness. 'Online Weiguan' then is the expression of China's collective consciousness captured in a moment that is emotionally mobilised by a collective chattering. It proposes judgements, solutions, blame, and actions, even while under state media political censorship, but crucially never forming into organising solutions or outside collective actions or protest responses. Online Weiguan in combination with citizen journalism, eyewitness reporting, and independent investigation, can be initiated by public citizens. Investigative journalism becomes a mediated mobilisation with a collective consciousness in the public sphere.

Chinese social media users on WeChat or Weibo often respond in unpredicted ways to highly sensitive issues under China's reactive yet often confused media censorship environment. In our case study, the \#MeToo movement (see Figure 5), with its focus on specific cases that are often later reported as news stories, works toward building campaigning activism (Han 2019).

The discourse within the Chinese \#MeToo movement is primarily an online emotional discussion dominated by complaints about the absence of reporting known cases as well as expressions of frustration about general ignorance among citizens (Han 2019). The 'bystander effect' - turning a 'blind eye' to witnessed events for fear of involvement - is a common complaint. Discussion rarely offers rational critical thinking or guidelines for solutions.

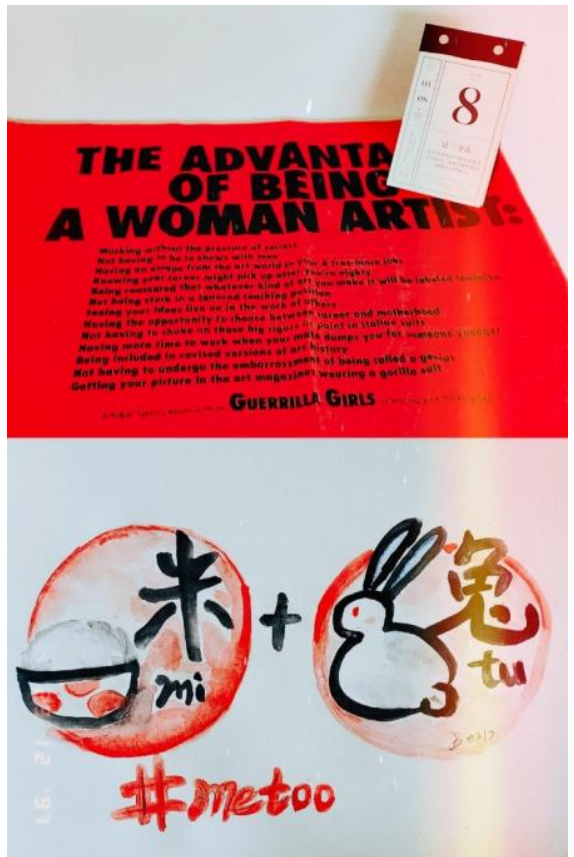

Figure 5: The \#MeToo movement that swept China in 2018 is regarded as a landmark event of the feminist trend to "become well-known among passers-by" in China. "Rice bunny" (米兔), pronounced as "mi tu", is a nickname given to the \#MeToo campaign by Chinese social media users. The \#RiceBunny hashtag, accompanied by emojis of rice bowls and bunny heads, is used by Chinese women to expose sexual harassment - often in conjunction with other Chinese hashtags, such as \#IAmAlso (\#我也是) and \#MeToolnChina (\#MeToo 在中国). (Drawing by Bao Han, 2021.)

Online Weiguan can be considered to be the equivalent of the similar crowd phenomenon activity in the West, identified in social psychology as the bystander effect. Such mass psychological events are often viewed as an odd phenomenon in large modern populated human societies. Social behaviours in China and the West differ as generally Chinese individuals are socialised into a complex networked collectivist society and in the West, it is much more constructed around the individual.

From fieldwork observations (Han 2021), we argue that virtual actions have established a form of collective intelligence and levels of citizen participation (Wu 2018) that has provided an impetus for forms of broader political modernisation. Netizens utilise Weiguan online as an alternative form of political involvement, which is generally prohibited at least not encouraged.

Online Weiguan is affordable and practically empowers those equipped with digital devices and social media to observe the internet as their window on public events. For government surveillance agencies, it evokes the question from the ancient Romans: "Who will guard the guards themselves?" 
There are various Weiguan characteristics. For example, it can occur due to online media event agenda-setting, following agenda-setting theory (McCombs et al. 2014), where the media influences the topics of interest to the public. The initial stage of this digital agenda-setting is online Weiguan.

Compared with traditional offline precedents, online activism through social media emotional mobilisation has the following features related to online Weiguan culture. There have three main characteristics.

Firstly, online Weiguan is a transformative crowd activity where there is participation in the public sphere of online topics. Online netizens' curiosity and crowd mentality offer opportunity, motivation, and political involvement to achieve political change. In the history of Western crowd contexts, crowd activity is usually taken as an alternative world with social protest and has the potential to enable social and political change. The studies of crowds in this context includes and extends to strikes, riots, rebellions, revolutions, aggressive mobs, hostile outbursts, and political demonstration. From interviews, a larger group of netizens, even among the scholars within a particular topic background, prefer to participate in Weiguan rather than express their opinion directly on a current sensitive event such as the \#MeToo movement, the interviewee, Maishao Tongxue (see Figure 6), cited:

"Silence is the true friend that never betrays. If what one has to say is not better than silence, then one should keep silent."

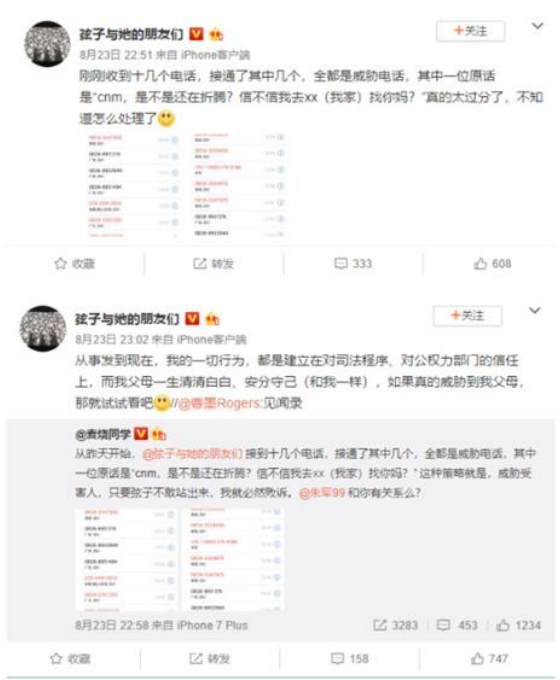

Figure 6: Weibo page by Xianzi and her friends, 2018. Content translation: "I just received more than a dozen calls and connected to a few of them, all of which were threatening calls. All my actions have been based on the trust in the judicial process and the public authority. My parents' life is innocent, safe, and self-preserving, just like me, if it really threatens my parents, we will see." This content received 491 comments and 1,355 likes. (https://m.weibo.cn/6640656158/4276315697732955)
Maishao's friend Xianzi, also on Weibo (see Figure 7), worked at CCTV as an intern, where she was molested by a well-known male celebrity (Han 2021). Maishao supported Xianzi and they decided to publicise the incident on Weibo, using pictured articles to avoid censorship by the authorities. This was an important climactic moment for the \#MeToo movement in China during 2018. The case reached the China law courts in 2020 ( $\mathrm{Ni} 2020$ ).

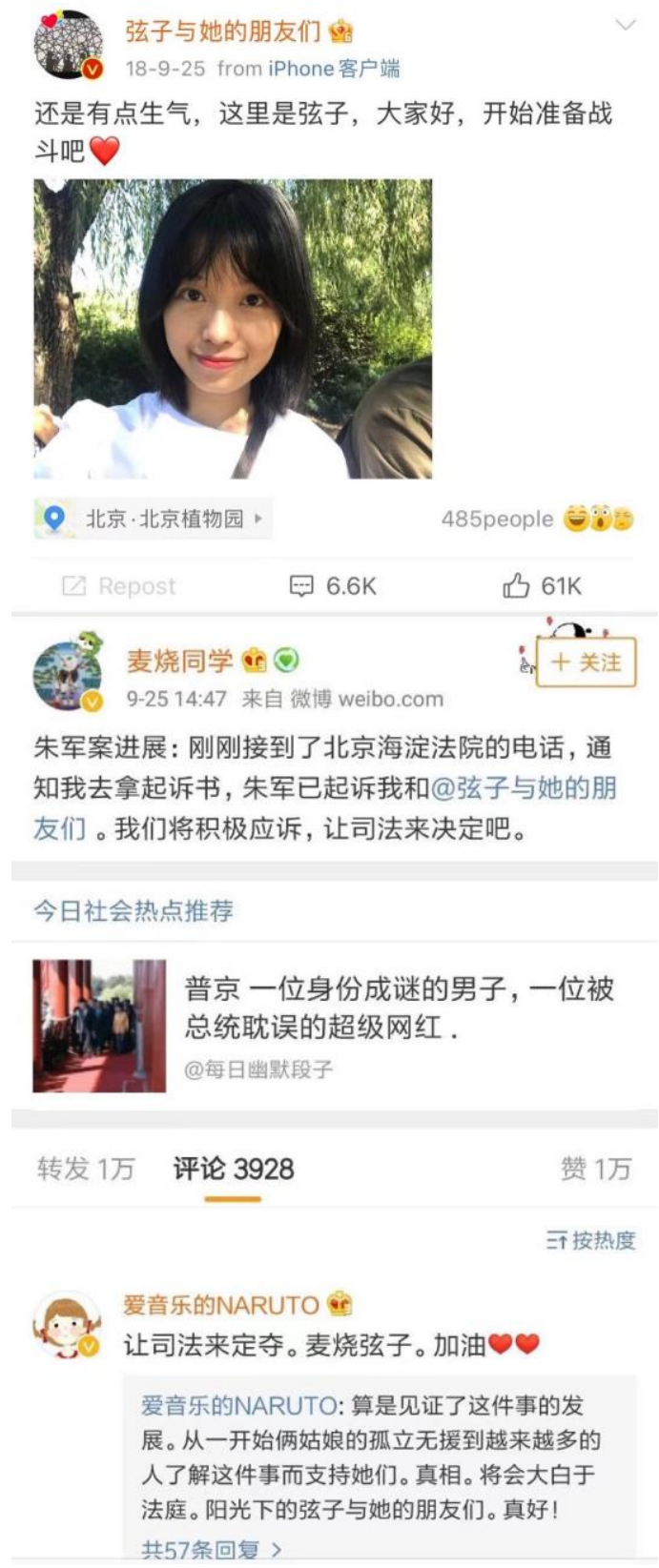

Figure 7: Weibo page by Xianzi and her friends, 2018. This content received 6.6k comments and 61 likes. (https://m.weibo.cn/6640656158/4288151323617951)

The Weiguan phenomena makes use of 'show and shame' rituals, a technique used throughout Chinese feudal history and formalised during the Communist revolution, to mobilise public emotions against selected targets. Any power for ordinary citizens forming as a crowd has become a 
double-edged sword. However, online Weiguan accelerates the Chinese Communist party to achieve its political purposes offline but also empowers the ordinary citizen to exercise supervisory and monitoring power over its governance.

Secondly, online Weiguan needs an emerging group or gathering crowd. However, due to the internet's features, the online Weiguan theoretically could enable more heterogeneous participants rather than the physical collaboration of participants. The online netizen becomes collaborative, based on their interests and voluntary participation. Due to the development of the internet, it is much simpler than before to participate in a protest, discussion, or scheme. Crowdsourcing is related to concepts, such as 'citizen science', 'wisdom of crowds', and 'public engagement' (Hedges \& Dunn 2017).

Discussion also frequently appears on the Chinese Zhihu (https://www.zhihu.com) question and answer web platform, which is similar to the Western Quora website. When investigating public online topics and monitoring Weibo comments, it becomes evident that the Weiguan phenomenon is one of the most important collective actions in present-day China as virtual, decentralised, leaderless, and networked action. It expresses social disagreement, grievance, and dissent, giving the opportunity to form gatherings of public opinion and create open critiques and public awareness against governance, which are still tightly controlled, since interventions are highly risky. It promotes and leads to a way to perform supervision by public opinion (yunlun jiandu 與论监督) (Xu 2015).

Thirdly, online Weiguan is mostly based on discursive communication, with few corresponding offline actions. Slacktivism is generally believed to be derogatory using social media to support protests, which eventually brings self-satisfaction and confidence as well (Christensen 2011; McCafferty 2011).

In Han (2021), we discuss the view that China online activism can be divided into two historical periods. 2003 can be considered as the watershed year in online public opinion that divides national internet Weiguan events in China. We argue that online Weiguan should be considered as a democratic practice to engage citizens in China, enabling debate of current topics and participation in social discussions.

\section{THE BYSTANDER EFFECT ONLINE}

Any cultural difference between the bystander effect and Weiguan may have different historical roots. However, the largest impact on these psychosocial phenomena globally today has been the ubiquitous use of the smartphone. To illustrate the universality of its impact, consider the example of an incident in 2017, where footages of a Vietnamese person being forcefully dragged off a flight in the USA by airline security was uploaded by passengers and disseminated quickly around the globe. The incident was covered in the West as injustice and an overreaction. In China, due to the passenger being of Chinese origin and therefore part of the group, this was seen as an outrage by Westerners against one of their own. The collective focus, as with many YouTube postings, moved quickly onto the next source of outrage. However, this recorded moment exemplified a common experience, in that, other than one woman loudly questioning the brutality upon this individual, the plane was full of quiet passengers. Hardly anyone else objected; a few held up their phones and recorded what was in front of them. The calmness of the scene was a precursor to the anger that later appeared on social media worldwide.

The assault, while in progress, had many passengers record the event using mobile phones. The instinct was not to speak out or intervene in the outrage but to record enough to preserve the incident digitally. Documenting without facilitating is a modern symptom of the distancing that occurs in the bystander effect. Does the inclusion of recording events on a smartphone mean a partial engagement with the event and a break with the idea of apathy in the observer? A similar even more dramatic example has been the 2020 killing of an unarmed black man, George Floyd, by a white US policeman through kneeling on his neck, recorded on a mobile phone and proving to be a galvanising incident in the "Black Lives Matter" movement.

The bystander effect has two key factors attributed to it. First is that of an apparent dispersion of duties: waiting for others to intervene first by way of confirming that it is the right thing to do. Secondly is one of social influence. This is where people become indifferent as they see no actions are being taken by others. We are surrounded by recording devices and sometimes imagine ourselves as activists. However, we become bystanders as documenting rather than participating is undertaken daily. Self-identification is somewhat different online compared to the real world. The mismatch is greatest when encountering acquaintances or strangers. These issues have been part of the ethics underlying photojournalism for decades. When is it appropriate to intervene rather than capturing an image? Is human neutrality realistic or ethical in crises? However, anyone with a smartphone often might find themselves making such split-second decisions believing in the long-term power of capturing an image rather than their abilities to affect an outcome at that moment. 
Culturally, there are layers of disembodied feelings when in public spaces, where a series of spectacles distract us as we interact with the world as bystanders and we stand and spectate. We become less able to assess our abilities in interventions and knowing the appropriate actions when the situation demands immediate action. In recognising this dilemma, we can hopefully reverse the notion that documenting is necessarily better than participating. Videoing events cannot automatically release us from interfering in emergent events. The smartphone also acts as a witness, intentionally or otherwise, of the crowd itself. The crowd is observed observing and therefore the term 'unethical witnessing' can be used in this context. Viral videos that incite outrage and produce emotional responses to a sense of justice demonstrate a dilemma in acting in accordance with our perceived values. Citizens need to be aware of the necessary transition from documenting to participating in that instant moment of decision when we are needed.

Fox-Glassman and Weber (2016) from Columbia University in New York investigated the bystander effect from a psychological perspective with danger perception, resolution, and judging as the key focus. A question raised in a group is do mobile phones deteriorate the situation? It is suggested that morbid curiosity may be involved but that videoing of an event and collecting evidence protects the person making the recording and offers the victim potential future justice. It is as suggested, a world where evidence is increasingly contested due to technological manipulations and giving verbalised first-hand accounts are insufficient even when being identified as being from someone of 'good character'. The perception is, in an increasingly hyper-competitive world, to win requires contesting evidence with one owns recorded evidence. The smartphone is weaponised for evidence. The encouragement to film situations is seen hopefully to aid in the removal of ambiguity. However, the studies crucially reveal that the level of threat is inversely related to the bystander effect. It is suggested that citizens will stand together in a local community rather than with strangers, since peer pressure and acquaintances tend to incentivise people.

Psychological research in the West and similar attempts in China to support authorities in developing citizenship in the forms of self-policing and first responders is extensive. Today, with mass public surveillance and the citizen's ability to record incident and events on smartphones, the average person has never been more under a critical gaze of their individual and group behaviours. The sense of obligation we carry as responsible citizens has never been more acute and critically observed. Online and offline behaviours both impact on each other in this regard. Being identified and named while observed in the worlds that we inhabit is very different to being an anonymous bystander within an in-crowd or experiencing being in the out-group. We recognise and feel these be profoundly different experiences and that affects how we act, vocalise, and behave, as we are unconsciously assessing our place during moments.

\section{CONCLUSION}

Weiguan has appeared as a Chinese phenomenon of real-world influence historically and more recently in online communications. Weiguan is a descriptive euphemism of group passivity in China. In this paper, we have examined the online Weiguan phenomenon in China, especially in the context of social media.

Online Weiguan can be understood is an internetmobilised collective action with a long cultural and political history in Chinese society and has rooted itself in contemporary online public internet culture. The participatory 'panopticon power' (Cascio 2005) structure or a synoptic system of power (Mathiesen 1997) equipped with digital devices carries out constant political censorship through collective interventionism.

For the future, digital citizenship is increasingly important culturally worldwide, including for the arts (Borda \& Bowen 2021). Social media changes can affect individual online behaviours. For example, Twitter has started to mark state-affiliated tweets, including official Chinese accounts, which has reduced the number of "likes" and "retweets" (Schoenmakers \& Liu 2021). At least the Chinese state social media accounts are not so extreme as to be banned, unlike those of a recent President! Ultimately, social media has the power to undermine democracy if allowed to do so (Vaidhyanatham 2018).

\section{REFERENCES}

Bandurski, D. (2011) The Surrounding Gaze 围观. China Media Project (CMP), 4 January 2011. https://chinamediaproject.org/2011/01/04/thesurrounding-gaze-围观/

Black, S., Bowen, J. P., and Griffin, K. (2010) Can Twitter Save Bletchley Park? MW 2010: Museums and the Web Conference, Denver, Colorado, USA, 13-17 April 2010. https://www.museumsandtheweb.com/biblio/can twitter save bletchley park.html

Black, S. and Colgan, S. (2015) Saving Bletchley Park. London: Unbound.

Borda, A. and Bowen, J. P. (2021) The Rise of Digital Citizenship and the Participatory Museum. In Weinel et al. (2021), this volume. 
Bowen, J. P. and Copeland, B. J. (2017) Turing's legacy. In Copeland et al. (2017), chapter 42, pp. 463-474.

Bowen, J. P. and Giannini, T. (2014) Digitalism: The new realism? In K. Ng, J. P. Bowen, and S. McDaid (eds.), EVA London 2014: Electronic Visualisation and the Arts. BCS, eWiC, pp. 324-331. DOI: 10.14236/ewic/eva2014.38

Bowen, J. P. and Giannini, T. (2021) Digitality: A reality check. In Weinel et al. (2021), this volume.

Cascio, J. (2005) The Rise of the Participatory Panopticon. WC Archive, Open the Future, 7 May 2005. http://www.openthefuture.com/wcarchive/2005/05/the ris e of the participatory.html

Christensen, H. S. (2011) Political activities on the Internet: Slacktivism or political participation by other means? First Monday, 16(2).

https://firstmonday.org/article/view/3336/2767

Copeland, B. J., Bowen, J. P., Sprevak, M., Wilson, R. J., et al. (2017) The Turing Guide. Oxford University Press.

Darley, J. M. and Latané, B. (1968) Bystander intervention in emergencies: Diffusion of responsibility. Journal of Personality and Social Psychology, 8(4, part 1), pp. 377-383. DOI: $10.1037 / \mathrm{h} 0025589$

Fei, X. (1947) From the Soil. Translated into English by G. G. Hamilton and W. Zheng, University of California Press, 1992.

Fox-Glassman, K. T. and Weber, E. U. (2016) What makes risk acceptable? Revisiting the 1978 psychological dimensions of perceptions of technological risks. Journal of Mathematical Psychology, 75, pp. 157169. DOI: $\underline{10.1016 / j . j m p .2016 .05 .003}$

Giannini, T. (2019) Contested Space: Activism and Protest. In Giannini \& Bowen (2019c), chapter 5, pp. 91111. DOI: $10.1007 / 978-3-319-97457-65$

Giannini, T. and Bowen, J. P. (2019a) Art and activism at museums in a post-digital world. In Weinel et al. (2019), pp. 27-35. DOI: 10.14236/ewic/EVA2019.4

Giannini, T. and Bowen, J. P. (2019b) Digital Culture. In Giannini \& Bowen (2019c), chapter 1, pp. 3-26. DOI: 10.1007/978-3-319-97457-6 1

Giannini, T. and Bowen, J. P. (eds.) (2019c) Museums and Digital Culture: New perspectives and research. Springer, Series on Cultural Computing. DOI: 10.1007/978-3-319-97457-6

Greenish, S., Bowen, J. P., and Copeland, B. J. (2017) Turing's monument. In Copeland et al. (2017), chapter 19, pp. 189-196.

Haidt, J. (2003) The moral emotions. In R. J. Davidson, K.R. Scherer, \& H.H. Goldsmith (eds.), Handbook of Affective Sciences, pp. 852-870. Oxford University Press.

Han, B. (2018). 枷锁与馈赠|认识真实的图灵，一位如谜 的解谜者. Tencent $\mathrm{QQ}$, People's Republic of China, 3 April.

https://mp.weixin.qq.com/s/JcdromoslivadmFmEf8SVQ

Han, B. (2019) 'Rice Bunnies' - \#MeToo in China: A hashtag movement and women's empowerment through social media. In Weinel et al. (2019), pp. 68-70. DOI: 10.14236/ewic/EVA2019.14

Han, B (2021) A Cultural Analysis of Online Citizen Activism in China. PhD thesis. Department of Digital Humanities, King's College London, UK. To appear.
Hedges, M. and Dunn, S. (2017) Academic Crowdsourcing in the Humanities: Crowds, Communities and Co-production. Chandos Publishing.

Lu, X. (1919) Medicine. Republished in Selected Stories of Lu Hsun, Beijing: Foreign Languages Press, 1960.

Mathiesen, T. (1997) The Viewer Society: Michel Foucault's 'Panopticon' Revisited. Theoretical Criminology, 1(2), pp. 215-234. DOI: $\underline{10.1177 / 1362480697001002003}$

McCafferty, D. (2011) Activism vs. slacktivism. Communications of the ACM, 54(12), pp. 17-19. DOI: 10.1145/2043174.2043182

McCombs, M. E., Shaw, D. L., and Weaver, H. (2014) New Directions in Agenda-Setting Theory and Research. Mass Communication and Society, 17(6), pp. 781-802. DOI: $10.1080 / 15205436.2014 .964871$

NPC (2017) General Provisions of the Civil Law of the People's Republic of China. Order of the President of the People's Republic of China, No. 66. The National People's Congress of the People's Republic of China, Chapter VIII. http://www.npc.gov.cn/englishnpc/lawsoftheprc/202001/c 983fc8d3782438fa775a9d67d6e82d8.shtml

$\mathrm{Ni}$, V. (2020) China \#MeToo: Court to hear landmark case of intern versus TV star. BBC World Service, BBC, 2 December 2020. https://www.bbc.co.uk/news/worldasia-china-55140026

Schneider, F. (2018) China's Digital Nationalism. Oxford University Press.

Schoenmakers, K. and Liu, C. (2021) China's Telling Twitter Story. China Media Project, 18 January 2021. https://chinamediaproject.org/2021/01/18/chinas-tellingtwitter-story/

Vaidhyanathan, S. (2018) Anti-Social Media: How Facebook disconnects us and undermines democracy. Oxford University Press.

Weinel, J., Bowen, J. P., Borda, A., and Diprose, G. (eds.) (2021) EVA London 2021: Electronic Visualisation and the Arts. BCS, Electronic Workshops in Computing (eWiC). ScienceOpen. DOI: 10.14236/ewic/EVA2021.0

Weinel, J., Bowen, J. P., Diprose, G., and Lambert, N. (eds.) (2019) EVA London 2019: Electronic Visualisation and the Arts. BCS, Electronic Workshops in Computing (eWiC). ScienceOpen. DOI: 10.14236/ewic/EVA2019.0

Wu, M. (2018) Weiguan and Meizhi: Modes of Civic Participation in Contemporary China. In Chinese New Media Cultures in Transition: Weibo and the Carnivalesque, chapter 4. Peter Lang. DOI: $10.3726 / \mathrm{b} 15312$

Xu J. (2015) Online Weiguan in Web 2.0 China: Historical origins, characteristics, platforms and consequences. In G. Yang (ed.), China's Contested Internet, pp. 257-282. NIAS Press of the University of Copenhagen. DOI: 10536/DRO/DU:30091601

Xu, J. (2016) Media Events in Web 2.0 China: Interventions of Online Activism. Sussex Academic Press.

$\mathrm{Xu}$, J. (2018) The politics of Weiguan in China's internet events. China Media Report, 1(65), pp. 23-28. DOI: 10536/DRO/DU:30106024

Yan, Y. (2010) The Chinese path to individualization. The British Journal of Sociology, 61(3), pp. 489-512, September. DOI: 10.1111/j.1468-4446.2010.01323.x 